\title{
An indirect fluorescent antibody technique for the diagnosis of Hematodinium sp. infection of the Norway lobster Nephrops norvegicus
}

\author{
R. H. Field, P. L. Appleton* \\ Division of Environmental and Evolutionary Biology, Institute of Biomedical and Life Sciences, Graham Kerr Building, \\ University of Glasgow, Glasgow G12 8QQ, Scotland, UK
}

\begin{abstract}
An indirect fluorescent antibody technique (IFAT) has been developed to detect Hematodinium sp. in the haemolymph and tissues of the Norway lobster Nephrops norvegicus. The IFAT, being more sensitive and reliable than previously used field and laboratory diagnostic techniques, detects both lower-level haemolymph infections as well as previously undiagnosable tissue infections. Lowlevel haemolymph and organ Hematodinium sp. infections have been found in apparently uninfected lobsters at all times of year, including late summer and autumn, when the parasite was previously thought to be absent from host lobsters. Currently, IFAT is routinely used for laboratory studies and the calibration of field diagnostic techniques.
\end{abstract}

KEY WORDS: IFAT diagnosis Hematodinium Nephrops norvegicus Parasitic dinoflagellate Crustacean disease

\section{INTRODUCTION}

Nephrops norvegicus, a common and commercially important decapod crustacean in Scotland, hosts pathogenic parasitic dinoflagellates of the genus Hematodinium (Field et al. 1992). Hematodinium spp. and Hematodinium-like organisms are becoming increasingly well known from a variety of crustacean hosts and geographical locations, often associated with mortality (Shields 1994). Such infections in N. norvegicus are widespread at certain times of year and the majority are thought to be fatal (Field et al. 1992).

Infection by Hematodinium sp. in Nephrops norvegicus has previously been diagnosed in the field by observation of the parasite in the haemolymph via the transparent cuticle of the pleopods (Field et al. 1992, Field \& Appleton 1995). The reliability and sensitivity of this method has been evaluated by direct observation of Hematodinium parasites in haemolymph smears stained with Leishman's stain (Field \& Apple-

- Addressee for reprint requests.

E-mail: 922725ap@udcf.gla.ac.uk ton 1995). The pleopod examination technique has also been used successfully for the diagnosis of Hematodinium in blue crabs Callinectes sapidus (Messick 1994).

Although pleopod examination provides a simple field diagnosis requiring little technical support, and the Leishman's stained smear has provided a more direct observational confirmation of diagnoses, use of these methods requires a degree of training. Moreover, although parasites are easily recognisable in the majority of haemolymph smears stained with Leishman's stain, experience is required for reliable diagnosis and, in cases of very light infection or poorly made smears, parasites can be hard to recognise or can be confused with certain classes of host haemocyte. Low numbers of Hematodinium sp. in haemolymph are often hard to detect in Leishman's stained smears, and therefore remain 'sub-patent' by current diagnostic methods. Although both these methods are valid, there is a need for a better, yet easily conducted, diagnostic test. Hence, an indirect fluorescent antibody technique (IFAT) has been developed. The IFAT can be used on a routine basis for the detection of Hematodinium sp. not 
only in haemolymph, but also in tissue samples. Since we have previously suggested that 'latent' tissue infection (Hematodinium sp. being present only in organs) may precede that of the haemolymph, the ability to diagnose infections in these tissues would improve the interpretation of field prevalence data obtained by haemolymph infection-based diagnostic methods.

\section{MATERIALS AND METHODS}

Antibody. A polyclonal antibody was derived from rabbits immunized with a mixture of vegetative forms of the infecting organism from in vitro culture (Vickerman et al. 1993). Parasite forms commonly observed in both haemolymph and tissues (Field \& Appleton 1995) from axenic cultures were used. Briefly, the methods (Harlow \& Lane 1988) included the following: washed pelleted cells from axenic culture were resuspended in Nephrops norvegicus saline and lysed by 3 cycles of freeze-thawing. Insoluble material was removed by mild centrifugation. Between 30 and $300 \mu \mathrm{g}$ of soluble protein (dependant upon the cultured parasite form) in buffered $N$. norvegicus saline was inoculated with an equal volume of Freund's complete adjuvant into 6 rabbits at 6 subcutaneous sites. Preimmunization control serum was collected from the test rabbits beforehand. After test bleeds, the 2 rabbits showing the highest titre responses were selected for further inoculation. Secondary, tertiary and quaternary inocula were injected with Freund's incomplete adjuvant every 4 wk, with further test bleeds taken 2 wk after each inoculation. Rabbits were exsanguinated $4 \mathrm{wk}$ after the final inoculation, and serum separated from clotted blood was frozen at $-70^{\circ} \mathrm{C}$ until required.

Indirect fluorescent antibody technique. The IFAT employed was similar to that described by Marks et al. (1992) for the diagnosis of Aerococcus viridans in lobster Homarus americanus haemolymph. The technique was applied initially to fixed smears of cultured Hematodinium sp. originally isolated from infected Nephrops norvegicus, and later to fixed smears of haemolymph from infected and control lobsters.

Haemolymph samples were withdrawn from the ventral haemal sinus of lobsters into a syringe containing $2 \%$ formol saline $(33 \%$ ) at a ratio of $2: 1$, allowed to fix for approximately $15 \mathrm{~min}$ and smeared onto clean glass slides. Culture material was smeared directly onto slides and fixed in ice cold $70 \%$ ethanol for $1 \mathrm{~h}$. Tissue smears were made by removal of organs from killed lobsters directly into fixative containing $2 \%$ paraformaldehyde and $0.1 \%$ glutaraldehyde, $4 \%$ sucrose and $3 \% \mathrm{NaCl}$ in $0.1 \mathrm{M}$ phosphate buffer, $\mathrm{pH}$ 7.4. Tissue samples were rinsed in $0.1 \mathrm{M}$ phosphate buffer containing $6.5 \%$ sucrose and stored in the same buffer, containing azide, at $4^{\circ} \mathrm{C}$ until required. Small pieces of tissue $\left(\sim 1 \mathrm{~mm}^{3}\right)$ were macerated and smeared onto clean glass slides. Tissue and haemolymph smears were then air dricd at room temperature and incubated in phosphate buffered saline (PBS) ( $\mathrm{pH} 7.2$ ) with $0.2 \%$ Tween 20 and either $3 \%$ bovine serum albumen (BSA) or $10 \%$ foetal calf serum for $15 \mathrm{~min}$. Slides were incubated for $1 \mathrm{~h}$ at room temperature with primary anti-Hematodinium sp. rabbit antibody diluted to 1:100 with $\mathrm{PBS} / \mathrm{BSA}$. Slides were washed with 5 changes of PBS/0.1\% BSA for 10 min each and incubated with secondary donkey antirabbit fluorescein labelled antibody (Scottish Antibody Production Unit) at a dilution of $1: 100$ with PBS/BSA plus $10 \mu \mathrm{g} \mathrm{ml}^{-1}$ 4',-6-diamidino-2-phenylindole (DAPI) (Sigma) as counter stain for $1 \mathrm{~h}$. Finally, smears were washed thoroughly with PBS/0.1\% BSA for $10 \mathrm{~min}$. Control slides were exposed to PBS/BSA containing no rabbit immune serum during the first incubation, or were incubated in preimmune rabbit serum. Control staining was also performed on smears of haemolymph containing another protist commonly found in moribund Nephrops norvegicus in captivity, a Paranophrys-like ciliate. Slides were mounted in 10\% PBS in glycerol with $25 \mathrm{mg} \mathrm{ml}^{-1}$ 1,4-diazabicyclo-[2.2.2]octane (DABCO) antifadant and examined using phase contrast and ultraviolet (UV) epifluorescence. Entire treated slides were examined for the presence of immunoreactive dinoflagellates under a low power objective $(\times 10)$. Upon detection of parasite material, the relative proportions of haemocytes and parasites were calculated after a total of approximately 400 cells were counted and identified. A characteristic of Hematodinium spp. is that many individual parasites are multinucleate, therefore counts were based on the number of nuclei of parasites or haemocytes stained by the DAPI nuclear counter stain. Quantitative counts of parasites from tissue smears were not possible, so presence or absence of parasite material alone was recorded.

Collection and maintenance of lobsters. Lobsters Nephrops norvegicus (25 to $35 \mathrm{~mm}$ carapace length) were caught by bottom trawling around the Isle of Cumbrae, Clyde Sea Area, Scotland, and maintained in a closed seawater system at $10^{\circ} \mathrm{C}$ and $33 \%$ salinity prior to use in experimental work.

Experimental comparison of diagnostic methods. Haemolymph samples were obtained from a total of 165 lobsters in spring and summer 1994, and both the status of Hematodinium sp. infection (Field et al. 1992, Field \& Appleton 1995) and moult stage (Aiken 1980) were determined by pleopod examination. One haemolymph smear from each lobster was immunostained as described, and one was stained with Leishman's stain (Field \& Appleton 1995). Haemolymph smears were 
examined microscopically to record the presence or absence of dinoflagellate parasites observed with each staining method.

Detection of latent Hematodinium infection using IFAT. Staining by IFAT was used to determine whether latent (not detectable in haemolymph by current diagnostic methods) Hematodinium sp. infections were present in adult Nephrops norvegicus at different times of year Previous work showed that detectable infections were present in $N$. norvegicus populations only during spring (Field 1992, Field et al. 1992). However, evidence from pathology and in vivo studies suggested that latent and/or subpatent infections may be present at other times of year (Field \& Appleton 1995, unpubl. obs.). Between 11 and 30 individuals were collected in January, February, March, August, October and November 1994. Lobsters were selected at random from trawl samples, but were all diagnosed as uninfected by pleopod examination. Thereafter, haemolymph smears were made from each individual. Tissue smears were prepared from samples of hepatopancreas, midgut, heart and abdominal muscle removed from lobsters killed by decapitation. Both haemolymph and tissue smears were immunostained and examined for the presence of fluorescing parasites.

Despite the range of different fixation methods used for parasites in culture, haemolymph and tissue
Samples, there was no difference in the reliability or sensitivity of immunostaining (results not shown).

\section{RESULTS}

\section{Evaluation of Hematodinium antibody and the IFAT}

Staining of Hematodinium sp. in haemolymph smears by IFAT showed good antibody specificity for the parasite (Fig 1). Host haemocytes were unreactive whilst background staining and autofluorescence were low in haemolymph smears. Although there was no binding of the antibody to host cells in tissue smears (Fig. 2), there was a degree of autofluorescence, especially in the hepatopancreas. This autofluorescence was minimised by ensuring thorough maceration of samples. All controls tested gave negative results, the rabbit antibody showed no affinity for host haemocytes or ciliates and there was no non-specific binding of the secondary donkey antirabbit antibody.

\section{Comparison of diagnostic methods}

The accuracy of pleopod diagnosis of Hematodinium sp. infection compared with 2 methods of haemolymph examination is shown in Table 1 . This assessment is
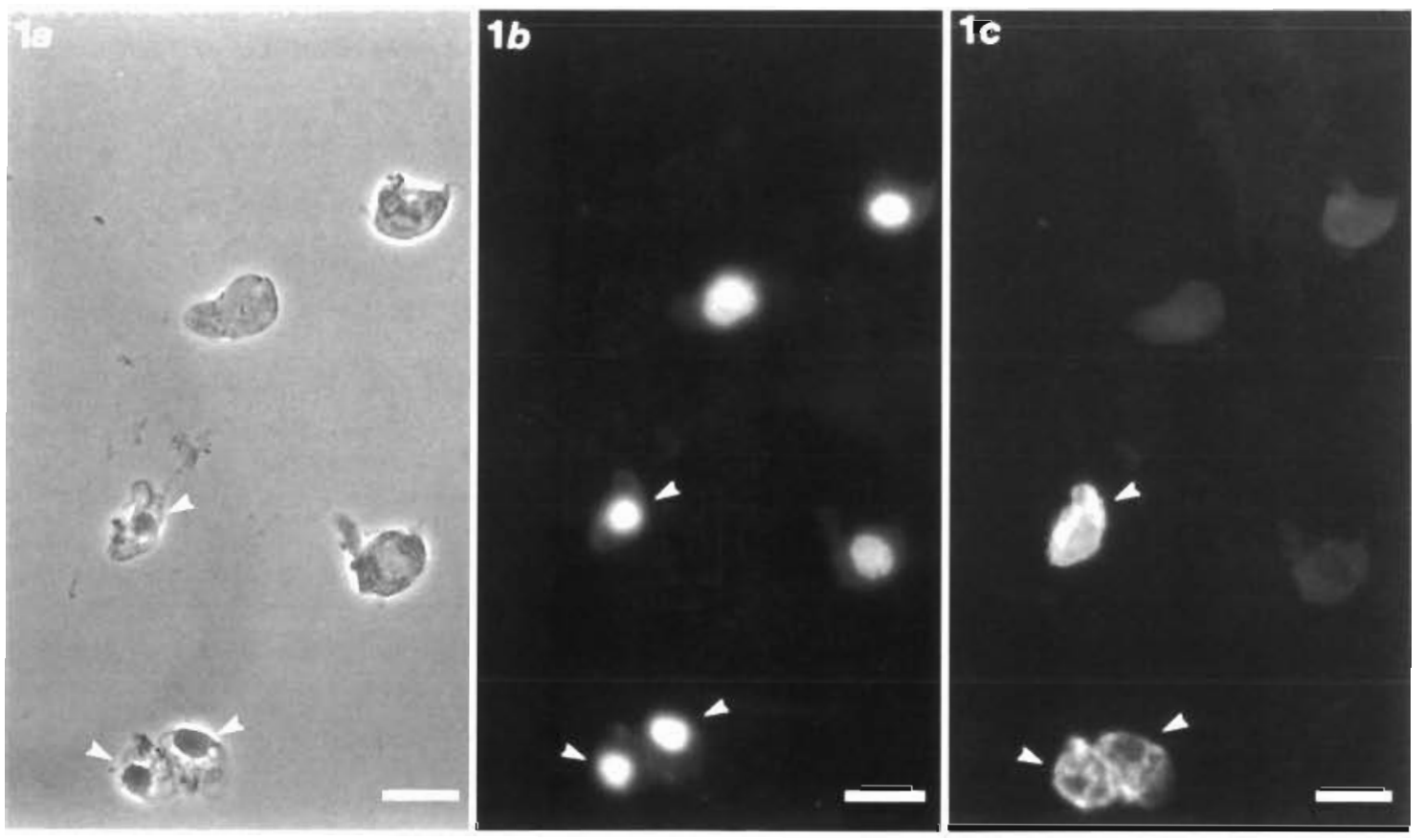

Fig. 1 Light micrographs showing specific labelling of Hematodinium sp. parasites by IFAT in a fixed Nephrops norvegicus haemolymph smear: (a) under phase contrast illumination; (b) under UV epifluorescence, showing DAPI nuclear counter stain; (c) under UV epifluorescence, showing labelling of Hematodinium sp. with fluorescent antibody while haemocytes remain unlabelled. Arrows: Hematodinium sp. parasites. Scale bars $=20 \mu \mathrm{m}$ 


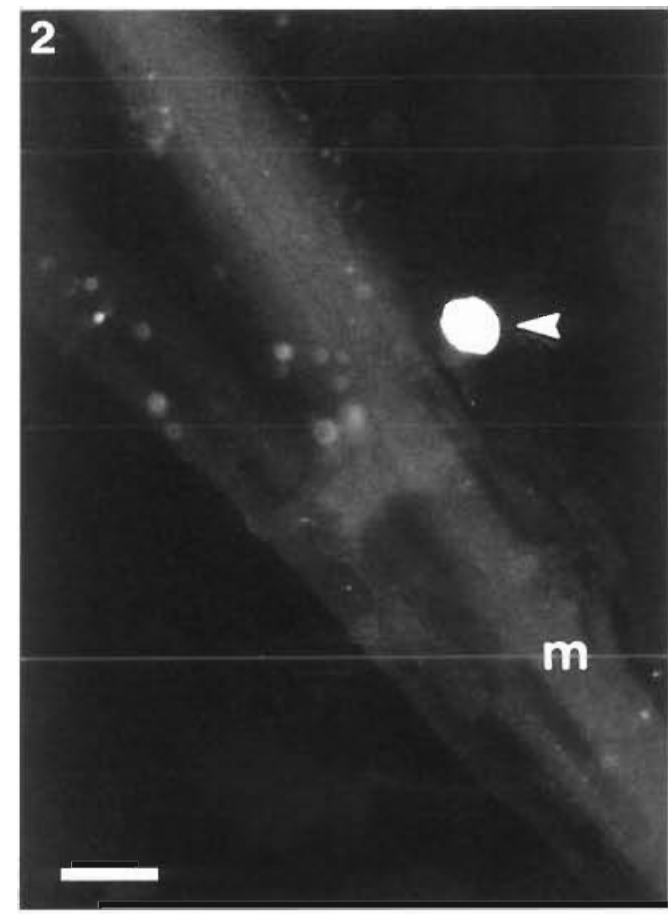

Fig. 2. Light micrograph showing a fluorescently labelled Hematodinium sp. parasite next to unlabelled abdominal muscle in a fixed Nephrops norvegicus tissue smear. m: abdominal muscle; arrow: parasite. Scale bar $=20 \mu \mathrm{m}$

based on the parallel examination of both sexes of lobsters by all 3 methods. Of those lobsters examined, $25(15.1 \%)$ were diagnosed as infected by pleopod examination. Examination of Leishman's stained

Table 1. Comparison of the accuracy of pleopod diagnosis of Hematodinium sp. infection with 2 methods of haemolymph staining

\begin{tabular}{|lccc|} 
& Pleopod & $\begin{array}{c}\text { Diagnostic method } \\
\text { Leishman's stain }\end{array}$ & Immunostaining \\
\hline $\begin{array}{l}\text { Number of lobsters/165 } \\
\% \text { prevalence }\end{array}$ & 25 & 34 & 37 \\
\hline
\end{tabular}

haemolymph smears revealed 34 individuals were harbouring Hematodinium sp. in their haemolymph $(20.6 \%)$. Immunostaining detected $37(22.4 \%)$ individuals within the sample that were infected, 12 more than by pleopod and 3 more than by Leishman's stain. Three individuals were diagnosed as infected by immunostaining alone. No infected lobsters diagnosed by pleopod examination were classified as being uninfected by other methods. All misdiagnoses by pleopod examination and Leishman's staining were made in lobsters initially staged as uninfected by pleopod examination but subsequently found to be infected by immunostaining or both smear examination methods. Those subpatent infections detected by immunostaining but undetected by Leishman's stain showed the lowest proportions of parasites to haemocytes, ranging from 0.3 to $1.7 \%$ (1 parasite: 383 haemocytes, and 6:346 respectively). The lowest proportion detected by Leishman's stain was $2.4 \%(9: 366)$.

\section{Detection of latent Hematodinium sp. infection by immunostaining}

Throughout the year, lobsters diagnosed as uninfected by pleopod examination were, in fact, harbouring subpatent or latent Hematodinium sp. infection detectable by IFAT (Table 2). Lobsters that contained parasites only in the tissues (latent infection), with no detectable haemolymph infections, were found at all times of year. During most of the year, some lobsters were infected with parasites in both the tissues and haemolymph. Parasite numbers were low in all haemolymph infections found in this part of the study.

In all cases of tissue infection where haemolymph infection also occurred, parasites in the tissues were abundant and represented all tissue forms so far described (Field et al. 1992, Field \& Appleton 1995). Well-established network syncytia were often observed in

Table 2. Results of fluorescent antibody survey for prepatent Hematodinium sp. infection of Nephrops norvegicus between January and November 1994. Hp: hepatopancreas

\begin{tabular}{|c|c|c|c|c|}
\hline \multirow[t]{2}{*}{ Month } & \multicolumn{2}{|c|}{ Number infected } & \multirow[t]{2}{*}{ Total infected/sample size } & \multirow[t]{2}{*}{ Infected tissues } \\
\hline & Haemolymph and tissues & Tissues & & \\
\hline January & 3 & 2 & $5 / 11$ & Muscle, midgut, $\mathrm{Hp}$ \\
\hline February & 2 & 2 & $4 / 30$ & Heart \\
\hline March & 0 & 1 & $1 / 12$ & Midgut \\
\hline August & 2 & 2 & $4 / 15$ & $\mathrm{Hp}$ \\
\hline October & 1 & 2 & $3 / 15$ & Muscle \\
\hline November & 2 & 2 & $4 / 15$ & Midgut, Hp \\
\hline
\end{tabular}




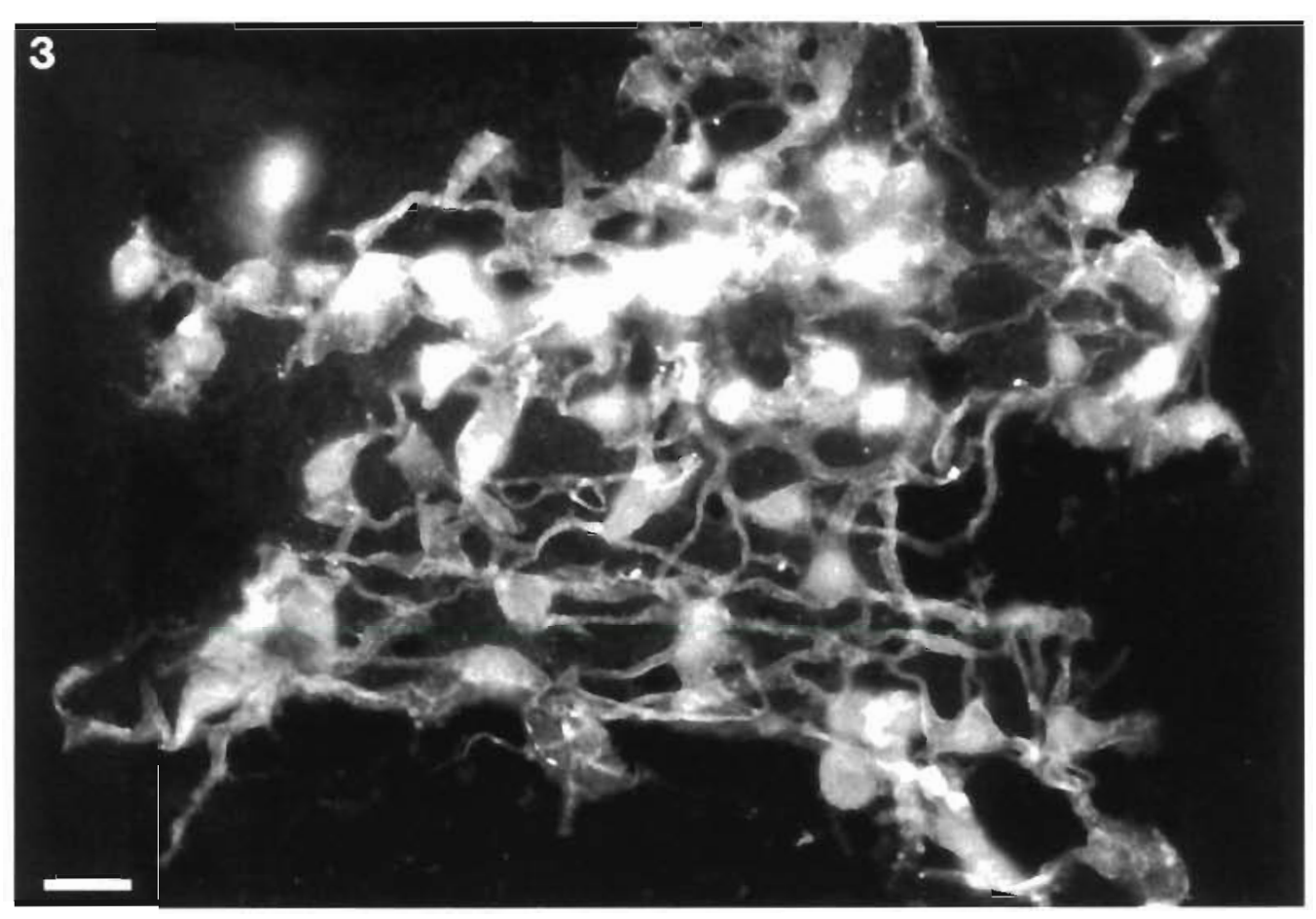

Fig. 3. Light micrograph showing fluorescently labelled multinucleate network-like parasite syncytium in a fixed hepatopancreas smear from Nephrops norvegicus. Scale bar $=$ $20 \mu \mathrm{m}$

abdominal muscle and hepatopancreas smears (Fig. 3) The observation of this form in the hepatopancreas increased the known range of tissue sites harbouring network parasites, previously known only within abdominal skeletal muscle and myocardial muscle (Field \& Appleton 1995). In all cases of tissue infection where no haemolymph infection occurred (latent) parasite abundance was lower.

\section{DISCUSSION}

The IFAT method described shows good specificity for Hematodinium sp. infecting the haemolymph and tissues of Nephrops norvegicus. The lack of crossreactivity of the antibody with host tissues or other commonly observed protistans makes this method suitable and effective for the identification of Hematodinium $\mathrm{sp}$ infection in both the haemolymph and tissues of infected lobsters. It is possible to identify dinoflagellate parasites while scanning slides at relatively low magnifications, unlike the detailed examination required of Leishman's stained smears. Although IFAT is only slightly more sensitive for detecting low-level infections than Leishman's staining $10.3 \%$ as opposed to $2.4 \%$ ), its unequivocal diagnosis and its relatively simple methodology make it the most reliable diagnostic method available. Pleopod examination remains the most suitable field method for disease diagnosis, but IFAT may be used to calibrate infection prevalence estimates made in the field. This calibra- tion may be particularly useful in the identification of Hematodinium sp. infections in previously unexamined or uninfected stocks. Furthermore, IFAT could be used to identify Hematodinium-like infections in new host species as well as from new geographical locations, though the affinity of this antibody for related or similar Hematodinium spp. from other crustaceans must be assessed first.

Use of IFAT for Hematodinium spp. from other host species represents a practical and potentially more sensitive detection and diagnostic method than those in current use. The benefits over pleopod examination and Leishman's stained smear examination will probably apply to the routine modified pleopod examination method used by Messick (1994) in blue crabs Callinectes sapidus and haemolymph examination methods of Meyers et al. (1987) in Chionoecetes bairdi.

The discovery of subpatent Hematodinium sp. infections in the haemolymph and latent infections in the tissues of apparently uninfected Nephrops norvegicus has other implications for surveys of infection prevalence which are made using the pleopod examination method. This initial, small-scale study has shown the number of subpatent and latent infections to be relatively constant throughout the year, irrespective of the number of patent infections observed. However, a larger-scale investigation would elucidate any possible seasonality of subpatent and/or latent infections. The presence of Hematodinium sp. parasites in the tissues of lobsters which showed no haemolymph infection appears to support the original hypothesis of Field \& 
Appleton (1995) that invasion of various organs occurs soon after acquisition of infection, before patent haemolymph infections are detectable. The presence of subpatent and latent dinoflagellate infections at times of year when the parasite was previously thought to be absent from host lobsters suggests a long latency and development period for infection, and that infection acquisition in one year leads to disease patency in the next or even later. Slow rates of parasite growth in vivo support this assertion (Field \& Appleton unpubl. obs.).

We now employ IFAT on a routine basis for both laboratory diagnosis and confirmation of field prevalence surveys made by pleopod examination.

Acknowledgements. This work was carried out with financial support from the ivinisisty of Aigriculiure, Fisileties and Fuvid. The authors also express gratitude to Dr C. M. R. Turner for assistance with primary antibody production and testing and critical review of the manuscript, to $\mathrm{Mr} \mathrm{J}$. Laurie for technical support and to 2 anonymous reviewers.

\section{LITERATURE CITED}

Aiken DE (1980) Moulting and growth. In: Cobb JS, Phillips BF (eds) The biology and management of lobsters, Vol 1 Academic Press, New York, p 91-163

Field RH (1992) The control of escape behaviour in, and the

Responsible Subject Editor: J. E. Stewart, Dartmouth, Nova Scotia, Canada histopathology of, the Norway lobster, Nephrops norvegicus (L.). PhD thesis, University of Glasgow

Field RH, Appleton PL (1995) A Hematodinium-like dinoflagellate infection of the Norway lobster Nephrops norvegicus: observations on pathology and progression of infection. Dis aquat Org 22:115-128

Field RH, Chapman CJ, Taylor AC, Neil DM, Vickerman K (1992) Infection of the Norway lobster Nephrops norvegicus by a Hematodinium-like species of dinoflagellate on the west coast of Scotland. Dis aquat Org 13:1-15

Harlow E, Lane DP (1988) Antibodies: a laboratory manual. Cold Spring Harbor Laboratory, Cold Spring Harbor

Marks LJ, Stewart JE, Håstein T (1992) Evaluation of an indirect fluorescent antibody technique for detection of Aerococcus viridans (var.) homari, pathogen of homarid lobsters. Dis aquat Org 13:133-138

Messick GA (1994) Hematodinium perezi infections in adult and juvenile blue crabs Callinectes sapidus from coastal bays of Maryland and Virginia, USA. Dis aquat Org 19: $77-82$

Meyers TR, Koeneman TM, Botelho C, Short S (1987) Bitter crab disease: a fatal dinoflagellate infection and marketing problem for Alaskan Tanner crabs Chionoecetes bairdi. Dis aquat Org 3:195-216

Shields JD (1994) The parasitic dinoflagellates of marine crustaceans. A Rev Fish Dis 4:241-271

Vickerman K, Appleton PL, Field RH (1993) Cultivation and development in vitro of a parasitic dinoflagellate (Hematodinium sp.) from the Norway lobster (Nephrops norvegicus). In: Abstracts of the IX International Congress of Protozoology. German Society of Protozoology and German Society of Parasitology, Berlin, p 131

Manuscript first received: July 5, 1995

Revised version accepted: September 19, 1995 